How to Share a Mind

Reconsidering the Group Mind Thesis

Szanto, Thomas

Published in:

Phenomenology and the Cognitive Sciences

DOI:

10.1007/s11097-013-9323-1

Publication date:

2014

Document version

Peer reviewed version

Citation for published version (APA):

Szanto, T. (2014). How to Share a Mind: Reconsidering the Group Mind Thesis. Phenomenology and the Cognitive Sciences, 13(1), 99-120. https://doi.org/10.1007/s11097-013-9323-1 


\section{How to share a mind: Reconsidering the group mind thesis}

\section{Thomas Szanto}

Phenomenology and the Cognitive Sciences

ISSN 1568-7759

Phenom Cogn Sci

DOI 10.1007/s11097-013-9323-1

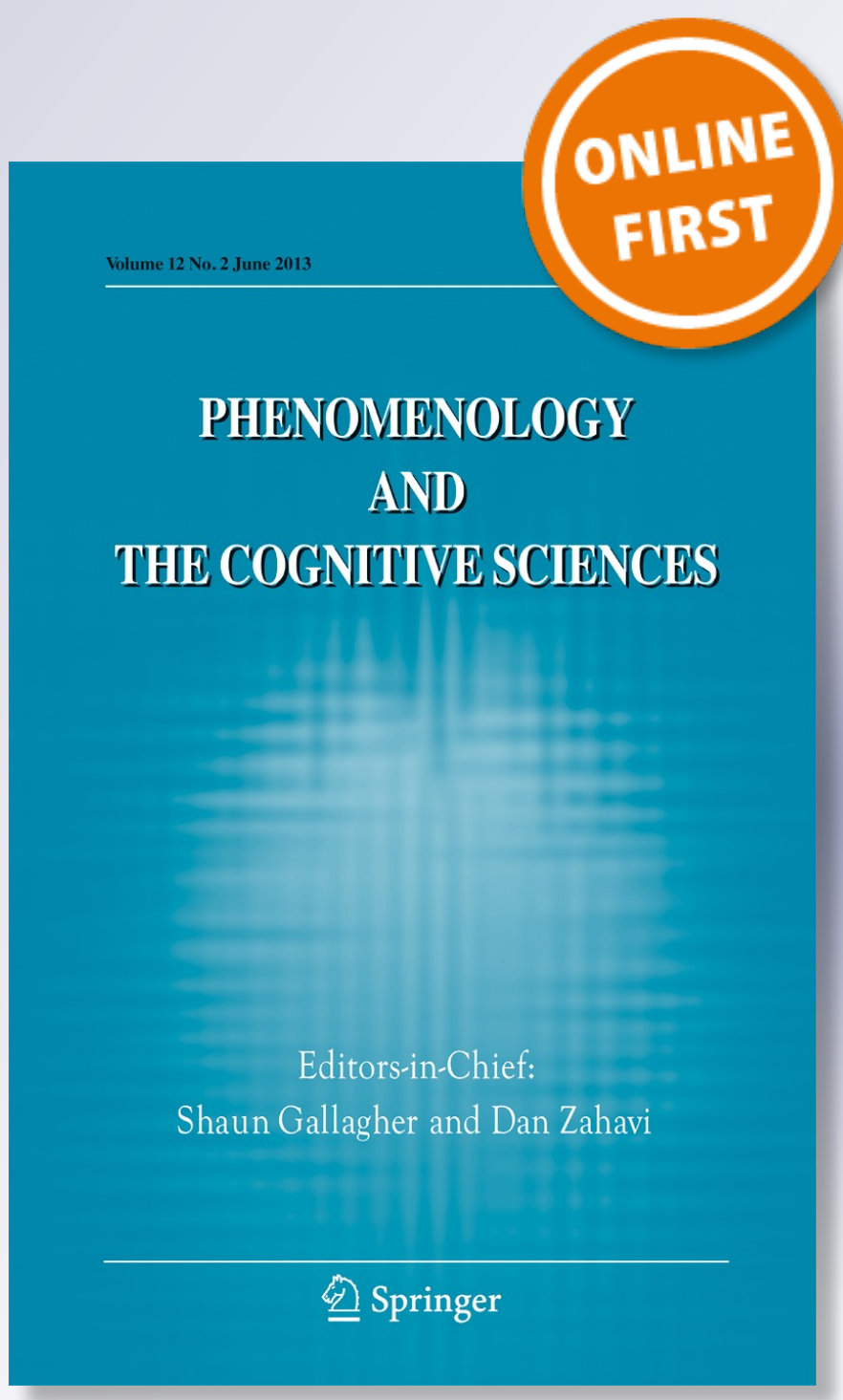


Your article is protected by copyright and all rights are held exclusively by Springer Science +Business Media Dordrecht. This e-offprint is for personal use only and shall not be selfarchived in electronic repositories. If you wish to self-archive your article, please use the accepted manuscript version for posting on your own website. You may further deposit the accepted manuscript version in any repository, provided it is only made publicly available 12 months after official publication or later and provided acknowledgement is given to the original source of publication and a link is inserted to the published article on Springer's website. The link must be accompanied by the following text: "The final publication is available at link.springer.com". 


\title{
How to share a mind: Reconsidering the group mind thesis
}

\author{
Thomas Szanto
}

(C) Springer Science+Business Media Dordrecht 2013

\begin{abstract}
Standard accounts in social ontology and the group cognition debate have typically focused on how collective modes, types, and contents of intentions or representational states must be construed so as to constitute the jointness of the respective agents, cognizers, and their engagements. However, if we take intentions, beliefs, or mental representations all to instantiate some mental properties, then the more basic issue regarding such collective engagements is what it is for groups of individual minds to share a mind. Somewhat surprisingly, this very issue has not received much attention in the respective debates and when it has, typically the outlook has been skeptical or outright negative. In this paper, I argue that it is epistemologically possible for a group of individuals to literally share a single mental unit. In particular, I will put forward and defend what I shall call the zombie conception of group minds.
\end{abstract}

Keywords Social ontology Collective intentionality - Group minds · Group cognition · Collective Consciousness · Anti-individualism

\section{Introduction}

The view that there may be mental properties that are not properties of individuals but properties of collectives, or the group mind thesis (GMT), has fallen into serious disrepute amongst philosophers. There are various well-known and, to be sure, justifiable political, historical, and sociocultural reasons for this being the case. However, I shall argue, there are no convincing epistemological reasons for rejecting GMT. Now, I concur with those critiques of GMT who insist that we cannot reasonably speak of collective intentions, desires, beliefs, representations, or group mental states unless we are prepared to attribute minds to groups (Rupert 2005). For,

T. Szanto $(\bowtie)$

School of Philosophy, University College Dublin, Dublin 4, Ireland

e-mail: thomas.szanto@ucd.ie 
arguably, mental properties and states are properties or states of minds. Hence, if we are prepared to attribute these to groups, then we better have an argument for the possibility of groups of minds constituting a single mental unit, or a group mind.

Here, I begin by defending what seems to me the most promising proposal of individuating group minds, namely by reference to their epistemologically autonomous, unified rational point of view ("Towards a non-minimal account: group minds as rational integrates"). I will then discuss the most important objection to GMT that groups cannot have phenomenal or conscious states, and I propose that we can deal with this objection by recognizing the possibility of what I call the zombie conception of group minds ("Epistemological restrictions on group minds: the zombie conception"). I will then defend this conception against a series of possible objections ("Objections and replies"). I conclude with an epistemological argument, the argument from epistemic irreducibility, which further supports the epistemological integrity of zombie-minded groups with their own rational point of view ("The argument from epistemological irreducibility").

\section{Towards a non-minimal account: group minds as rational integrates}

In ordinary language, we frequently come across the mentalistic idiom that describes what two or more individuals intend, think, or do together. We often and easily use this idiom when speaking of organizations, committees, corporations, sports teams, or political parties. "The committee really made a mess of that decision." "The team tried its hardest." "The corporation regrets the decision of its subsidiary to use child labor in its factory." "The two winning parties formed a coalition based on their shared values, expectations, and out of mutual self-interest." When speaking thus, most philosophers are inclined to say that what we are doing is either attributing intentional states by using shorthand for the sake of explanatory efficiency or just speaking metaphorically. We do not, and cannot, really mean, e.g., that the parties themselves literally have those states, or that their individual members literally share the party's own distinct attitudes, values, etc. What we mean is rather that all, or at least the majority of the members of the respective parties, share these views as individuals.

I contend that we are, in certain cases, right in using the mentalistic idiom and what is rather unwarranted is a certain, deeply entrenched, and broadly Cartesian intuition that lies at the heart of the predominant view. ${ }^{1}$ The basic argument that encapsulates this intuition runs like this:

1. To have a mind is to have (self-)conscious mental states with phenomenal content.

2. Groups do not have (self-)conscious mental states with phenomenal content.

\footnotetext{
${ }^{1}$ Note that there is a growing body of experimental philosophy work on folk intuitions about right and wrong usages of the mentalistic idiom when applied to collectives (even including phenomenal and conscious state ascriptions). This research suggests that we ought to considerably restrict our philosophical intuitions about what people really think or ought to think about collective mentality (cf., e.g., Huebner et al. 2010; Waytz and Young 2012).
} 


\section{Hence, groups do not have minds.}

I shall show that what is wrong with this argument is the equation of mindedness with phenomenally conscious mental properties in premise (1). This equation leads to the arguably untenable consequence that groups with minds of their own were to have some sort of collective consciousness. My strategy is to provide alternative epistemological criteria for individuating group minds and thus dissociate (collective) mindedness from consciousness.

Before doing so, however, it should be noted that this strategy is certainly not the only route currently available to challenge the conclusion (3) above. Notwithstanding prevailing orthodoxy against collective mentality, ${ }^{2}$ notably amongst those social ontologists who reject various forms of individualism (agential, methodological, or ontological; cf. Bratman 1992, 1993, 1997; Searle 1990, 2010; Miller 2001; Meijers 2003; Tuomela 2007, cf. also 2013), recent years have witnessed the emergence of new conceptual and empirical grounds for reconsidering GMT. Roughly, two main currents have recently come to attack the traditional geography of the mental as being exclusively confined to (organism bound or human sized) individuals: First, there is an increasing number of social ontologists who claim that there are "mental commons" (Baier 1997), "group agents" (List and Pettit 2011), "plural subjects" (Gilbert 1989, 1997, 2006), or "groups with minds of their own" (Pettit 2003a). However one refers to them: all these authors agree that these collectives have intentions, attitudes, aims, preferences, or beliefs, i.e., paradigmatic mental states of their own such that they cannot be properly explained, predicted, or evaluated solely by reference to facts about their individual members. ${ }^{3}$

Second, there is an ever-growing body of, largely empirical, evidence from research in social cognition that speaks for so-called socially distributed cognition (e.g., Hutchins 1995; Thompson and Fine 1999; Sutton 2006; Poirier and Chicoisne 2006; Smith 2007; Blomberg 2009), shared extended minds (Bosse et al. 2006, Gallagher 2013), collaborative or transactive memory systems (Wegner 1987; Wilson 2005; Barnier et al. 2008; Sutton et al. 2010), and, more generally, for the group cognition thesis (Gureckis and Goldstone 2006, 2009; Akkerman et al. 2007; Theiner et al. 2010; Theiner and O'Connor 2010). All these works strongly suggest that there are cognitive processes (such as representation, memory, learning, environmental control, problem solving, or creativity) which cannot be reduced to the cognitive architecture or capacities of individual cognizers or their aggregate. ${ }^{4}$

Typically though, when analyzing collaborative epistemic, cognitive, or practical activities, standard accounts in social ontology focus on the modes, types, or contents of the intentional states or, as in the group cognition debate, on specific cognitive processes, representational mechanism, or issues relating to their functional or computational architecture. I take a number of existing accounts to be adequate for

\footnotetext{
${ }^{2}$ For the by now classic modern statement of anti-GMT, see Quinton (1975/1976).

${ }^{3}$ See, in this vein, also Stoutland (1997, 2008), Velleman (1997), Tollefsen (2002b, 2002c), Schmitt (2003), Pettit and Schweikard (2006), Sheehy (2006), Schmid (2009).

${ }^{4}$ Some have claimed that socially distributed cognitive processes are best seen as collaborative cognition and at most distributed within individual minds but not across individual minds (Harnad 2005) or that while cognition may be distributed this does not go for knowledge or having a mind (Giere 2007). For a succinct critical review of the group cognition literature, see Rupert (2011), and for a concise discussion of how those two above-mentioned currents relate, see Tollefsen (2006).
} 
analyzing the formation of joint action, collective representations, and memory or the complex epistemic machinery of group reasoning and deliberation. In this paper, I do not intend to scrutinize any of these accounts or offer some alternative explanation of what is commonly labeled "collective intentionality"; nor shall I say much about group cognition. For I contend that there is a more basic issue involved in collective mentality than just jointness of intentional acts or act types and modes or collectively shared representational, intentional, or propositional contents. This is precisely the issue of what it is for individual minds to share a mind. Secondly, even though I agree with standard accounts holding that where there is cognition, intentionality, or (mental) representation, there are mental properties I believe that we should not rest satisfied with an account of "minimal collective minds" (Huebner 2011a; cf. also Wilson 2004, 290ff.) nor, for that matter, with those trading on functional parity between individual and group cognition alone (cf. Brooks 1986; Clark 1994; Theiner and O'Connor 2010; Theiner et al. 2010).

Now, unsurprisingly, there is no general consensus amongst philosophers of mind or cognitive scientists how to define the mental. Moreover, there is no agreement as to whether there are some essential properties available for such a definition, just as little agreement there is, incidentally, as to whether there is a mark of the cognitive. However, it is widely assumed that mental properties are those properties identified by folk psychological explanations citing beliefs, propositional attitudes, or desires. Their specific representational or cognitive functions, in turn, are the proper subject matter of the cognitive sciences and have some causal, explanatory, or predictive role as to the intelligent behavior of the systems exhibiting such properties. I concur with this, admittedly sketchy, standard picture of the mental.

This having been said, I take the attribution of mental properties to be a necessary but not a sufficient condition for there being group minds. For there to be full-blown collective mentality, there has to be a specific epistemically and temporarily robust integration of mental properties into one shared and collectively sustained, mental architecture. In other words, we can speak of a group mind only if the entity to which mental states are to be attributed is a single-minded entity. In particular, it is not a plural aggregate of (individual) mental states or properties but rather a "social integrate" (Pettit 2003a) of such. If this is the case, the properties of such an integrated mind can be genuinely shared by a plurality of minds precisely because they are properties of a single mental unit or a mind of its own.

Following what might be called the "integrationist approach" to group agency and personhood, exemplified in the work of Rovane (1998, 2004), Pettit (2003a, b), and List and Pettit (2011), here, then, are what I take to be necessary and jointly sufficient conditions for individuating such integrated minds. A group of individual minds $\mathrm{G}$ constitutes a full-fledged group mind if and only if it satisfies the following three interrelated requirements:

1. Intentionality requirement: $\mathrm{G}$ is an intentional system, that is, $\mathrm{G}$ bears intentional properties such that $\mathrm{G}$ can form, hold, and robustly entertain intentional states, viz. mental states with representational and propositional content, beliefs, and motivational pro-attitudes or desires (collective goals, aims, etc.) and (collective) intentions, where reference to such states figure in psychological explanations of the behavior of $\mathrm{G}$. 
2. Rationality requirement: $\mathrm{G}$ holds holistically construed, relatively consistent, noncontradictory beliefs, forms attitudes that are sensitive to factual evidences, ranks its preferences and values, and attends to them and their transitivity. It is sensitive to available means and options for attaining its goals, forms intentions on the basis of such options, preferences, values, and beliefs, and, in normal circumstances (i.e., if it is not subject to motivated forms of irrationality), reasons upon those beliefs and preferences and acts upon those intentions and pro-attitudes.

3. Integrity requirement: $\mathrm{G}$ integrates its intentional states so as to constitute an overall rationally unified point of view (RPV), i.e., a unified set of reasons, in the light of which $\mathrm{G}$ assesses its given beliefs, preferences, and intentions and which in the course of theoretical reasoning and practical deliberation yields conclusions as to what all-things-considered $G$ ought to believe and do. G can avow (by means of symbolic representation, verbal, or other discursive practices), acknowledge, and deliberately endorse the normative practical and theoretical conclusions provided by its RPV and, if necessary, modifies its beliefs, preferences, or intentions accordingly.

If these three requirements are satisfied, groups have an epistemically distinct integrated or unified rational point of view. Consider that, properly speaking, the social integrate constituting such a point of view has no mental parts that are compartmentalized across the mental states of individuals. To be sure, the mental properties of such integrated group minds are nothing over and above individual minds, as would be the case for a supra-individual "extra-entity", but are socially distributed over a single, holistic, rationally unified, normatively binding, and epistemologically contentful and thus evaluable mental system. However, none of the above criteria, nor all of them taken together, entail that there is one individual who instantiates such a group-level mental system. Rather, the social integrate supervenes on the rationally and normatively integrated set of mental states of at least two individuals that are, for their part, spatiotemporal entities. ${ }^{5}$ For the suggested proposal, it is crucial to see that the vehicle realizing a group mind is no individual entity with a spatiotemporally localizable body (or some other ontologically substantial entity) and hence, in this specific sense, there is no (individual or collective) bearer of such a mind. ${ }^{6}$ This is also the reason why I do not subscribe to formulations of group mentality such as Rupert's, one of the staunchest recent critics of GMT, according to which "group, or collective, mental states [are] mental states instantiated by a single individual that comprises two or more individuals who themselves have mental states." (Rupert 2011, p. 630) After all, it's groups that are supposed to have minds, not some (supra-)individual. ${ }^{7}$

\footnotetext{
$\overline{{ }^{5} \text { Here, I cannot go into specifying }}$ the supervenience relation mentioned or its ontological implications. Let me just indicate that I subscribe to construals of "holistic supervenience" between individual- and grouplevel mental properties, according to which, roughly, the content of group-level mental states is fixed by sets of rationally integrated individual-level states (with the respective contents); for more detailed accounts along these lines, cf. List and Pettit (2011, Chap. 3) and Currie (1984); see also Tuomela (1989).

6 This clause as to the "bearer" of group-level mental properties accounts for a construal of group minds that is fully compatible with a "nonentity view" according to which groups are no entities of any kind (cf. Tuomela 2007, p. 145).

${ }^{7}$ I take it, however, that my suggested integrationist construal of group mental units is well compatible with Rupert's "integrated set"-type definition of cognition, according to which "the cognitive status of individual states, then, derives from the relation between those states and the integrated, persisting cognitive system" (Rupert 2009, p. 41; cf. also Rupert 2011, p. 637), pace Rupert's own intentions, to be sure.
} 
Ultimately, the conditions of identity of such group minds are given by epistemological-cum-normative standards - standards that are identical to those regulating the formation of a group's unified rational point of view. Given that integration is supposed to be a rational process, it is not brought about due to some external third party or authoritative (nonrational) pressure. Nor are they accidental or mechanical reactions to environmental (social or other) demands but are constituted by the group itself, by its very sensitivity to the norms of practical and theoretical rationality. These norms are imposed on them by their rationally unified standpoint and these norms prescribe and guide the group's thoughts and actions. Such a group can be said not only to constitute but also to sustain its own rational integrity; accordingly, its rational standards are self-regulating as they must be both acknowledged by all members qua members and also conform to the rational point of view of the group itself. Thus, the group itself must keep and live up to these standards. That is to say that this standpoint normatively guides the formation of further attitudes, goals, and intentions and in light of which these are, if necessary, modified. Furthermore, it serves both for members and non-members as the basis for the normative and epistemological evaluation of (the coherence of) common attitudes, goals, intentions, etc. The group's "sensitivity" to such norms and rational standards can be specified in terms of a group's rational dispositions that consist, in particular, in minimizing inconsistencies between the perspectives of the members in view of some common goal and the overall group perspective. This means aiming at robust majoritarian views, minimizing disagreements between sub-parties or trying to solve them consensually, without falling prey to irrational sociopsychological biases, such as extreme "intragroup polarization," "pooling of information" (Sunstein 2002), or the infamous "groupthink" (Janis 1982).

Because this point of view is a rational point of view, there is a general normative implication involved. Although there is no substantial normative requirement on individual members, there is a corresponding structural collective requirement: the requirement to strive to establish such a unified and rationally coherent standpoint. Thus, groups may not only be held (collectively) responsible for their views, intentions, and goals but, moreover, for whether and how these cohere with one another and with the overall rational point of view of the group. In other words, groups are both rationally and normatively required to attend to the establishment of a coherent center of attitudes, beliefs, and intentions as well as to be receptive to the normative requirements of their thus established standpoint and to new reasons.

Clearly, there is more to be said on the organizational and holistic design and, more specifically, on the relevant interrelations that constitute the unified rational point of view of groups. Here, I can only hint at some of its key features. At the grossest level of integration, the following factors ensure that there is a unified rational point of view: There must be normatively binding rational meta-standards (non-contradictory voting procedures and aggregation functions, consistency and non-contradiction with other beliefs, goals and subgoals of the group) in order to merge the relevant attitudes. These standards have to be consensually agreed on by (some or all) members through deliberative procedures; eventually, there will be predetermined levels of expertise or even (non-authoritarian) hierarchies in order to rationally evaluate certain beliefs in view of certain group-level goals. 
What sorts of collectives may exhibit such rather complex epistemological integrity? Typical candidates for such groups are institutional, corporate, or organizational entities of a relatively complex internal structure. More generally, candidates are all collectives that have at least two individual rational members who act or reason on the basis of a set of intentional attitudes with respective (propositional) contents, intentions, or goals or else have some adopted collective or "corporate decision structure" (cf. French 1979) that robustly ensures such reasoning and rational action. Given specific amendments, such integration may also hold for the more basic, familiar cases discussed by social ontologists like Searle et al., typically using examples of collective intentions or shared cooperative activities in two-person interactions (such as carrying a piano, painting a house together, dancing tango, or walking together).

Suppose that Paul and Mary jointly intend to do some gardening together tomorrow and that they constitute the "plural subject" of the respective action by "pooling" their individual intentions to a collective intention, thus sharing a single intentional attitude. However, when they share that intention (regardless if one describes this sharing à la Searle, Bratman, or Gilbert), an essential element is missing in order for their collective intention to count as an intentional attitude of a shared mind. What is lacking is the fact that Paul and Mary may have a joint intention without either of them having some further attitude towards their joint intention, as, e.g., regarding what to do in case of raining tomorrow. If they do have such a further attitude, then what we have is a unified point of view that has a causal role in Paul and Mary's joint activity (and ipso facto a causal role for each of their individual activities). Such a further attitude may be dispositional, explicit, or eventually a sort of meta-belief. In the latter case, this would involve something like the conditional "If it's raining we are not going to do gardening," i.e., an attitude that provides them a collective reason to conditionally restrict or modify their shared intention without the necessity to form a new shared intention in each and every case of rain. In that case, we can say that they do share mental properties, however limited their epistemological and/or practical range might be. What this shows is that plural subjects of the sort discussed by Gilbert may or may not constitute a group with a mind of its own, depending on whether they involve a rationally interdependent or structured set of intentional attitudes or some collectively adopted deliberative mechanism. More generally, I take groups with such minds to be a sub-class of the genera of collectives.

As I shall argue below in more detail ("The argument from epistemological irreducibility"), what we can and should adopt from Gilbert's congenial plural subject approach to collective mentality, however, is the idea that a group can have mental states and, ultimately, a unified rational point of view without there being respective individual mental states (with any or the same epistemological content) or a personal commitment to the rational group point of view at all (Gilbert 1997, 2004, 2009). The rational point of view of groups, then, is not a function of the aggregation of the mental properties of individual states but rather a constitutional result of, or better, identical with the function of the rational integration of those states. 


\section{Epistemological restrictions on group minds: the zombie conception}

Now, suppose that one grants that there may be groups with epistemically distinct rational point of views. Skeptics might wonder what kind of mind such a rather abstract conception of group minds, individuated by their unified rational point of view, entails, and, more precisely, what kind of mental properties such minds exhibit. Moreover, critics of GMT might still resort to the initial basic argument, according to which groups have no minds because they lack the essential properties of minds, namely (self-)conscious or phenomenal properties. Here, I shall address these concerns and argue that social integrates indeed are zombie minded but nonetheless minded entities.

The point of departure is to make clear that groups, in fact, do not have the same epistemic kinds of mental properties as their individual members do. Social integrates are rationally but not phenomenologically integrated minds (cf. Rovane 1998, 2004). More specifically, there are two restrictions that accommodate the intuition that group minds cannot be phenomenally conscious or self-aware minds.

1. First, we have the epistemically privileged self-knowledge and immunity to misidentification restriction: groups neither have immediate, epistemically privileged self-knowledge of their actions, intentions, intentional contents or modes of their mental states, nor is a group's knowledge of them immune to certain types of misidentification.

I contend that no group has non-reflective or any kind of non-relational knowledge of the group having any mental states in the first place. Epistemic access to the group's mental properties is always non-direct, dynamic, or diachronic and discursively mediated: it is mediated and eventually made explicit by deliberation, votes, monitoring, and communication or like procedures. On the members' side, no member has the kind of privileged epistemic access to the group's we-mode point of view that she has in the first-personal case. There may be some more or less privileged accesses amongst members, varying even in considerable degrees (advisory board members will have more, factory workers less, etc.). However, the point is that these differences in privilege are differences only in degrees, not in kind, as is the case between first- and third-personal access to mental states.

Additionally, neither groups themselves nor, again, their members are immune to various types of misidentification. Individual members may misidentify the occurrent content of the group's attitudes or the scope of application of the "we-mode" either because they are ill- or misinformed or else because they misidentify others or themselves as group members. Moreover, the group itself may be mistaken about some collective agreement or acceptance of certain views; also the group may be mistaken about individual consent to certain shared beliefs.

Consider the individual case first. It is fairly common to assume that in individual, self-reflective or simple demonstrative I-thoughts, such as "I am thinking of my holiday last year" or "I am here", given ordinary circumstances, it does not make sense for subject of such thoughts to ask "There is a person $\mathrm{P}$ who is here, but is $\mathrm{P}$ $m e$ ?" The subject can, without any identification (of the sort " $\mathrm{P}$ is $\varphi$ and $\mathrm{P}=\mathrm{I}$ ") or empirical observation, directly refer to herself as the very subject of that thought (cf. Shoemaker 1968; Evans 1982). In contrast, the plural subject of "we-thoughts", 
precisely by being an integrate of subjects and not a single subject, is bound to make errors as to the scope of the "we" or, in extreme cases, whether there is such an integrated subject at all. Conversely, there is no single individual or instance of a collective that might, at any given time $t$, state with certainty or trustworthiness which occurrent mental states the group has at $t$. Again, the content of such states must be discursively negotiated and reassured anew relative to the prevailing standards of rationality and the specific goals of the group. In short, groups have only inferential or observational knowledge of their own states. The observation can be performed by internal or external supervisional panels, control committees, compliance experts, etc. which may be either subdivisions of the group, an individual member, or new instances of the group at a later point in time than that of the occurrent attitudes, thus constituting another exemplification of the same group.

2. Secondly, we have the self-awareness and consciousness restriction: Selfawareness and consciousness are, it's safe to say, notoriously ambiguous concepts. It is relatively uncontroversial, however, that consciousness involves not only an essentially first-personal character but also that subjects of conscious mental states are pre-reflectively aware of both (a) their being in a given mental state and (b) of the intentional mode (believing, fearing, and like act-qualities) and the content of their conscious states. ${ }^{8}$ Given this minimal construal, I hold that every proper conscious state $\mathrm{S}$ is a state that has intrinsically and necessarily a content and a mode that is intentionally given for the subject of $\mathrm{S}$. Furthermore, the subject of $\mathrm{S}$ is pre-reflectively aware of herself being in or entertaining S (cf. Szanto 2012).

For the present purposes, it is crucial to note that one can hold fast to the abovestated "intentionality requirement" ("Towards a non-minimal account: group minds as rational integrates") even if one holds that if a state is conscious, it necessarily has intentional content. Neither the claim that all conscious states are intentional (and hence mental) states nor the claim that intentionality is an essential property of consciousness entails that it is an essential property of the intentionality of mental states (where, likewise, all mental states are intentional) that these states are conscious states. $^{9}$

Self-awareness, to be sure, can be either reflective or pre-reflective. However, neither of these modes applies to groups, and the reason is not only that there is obviously no first-personal self-hood in groups. Consider reflective self-awareness, where a subject deliberately either turns her attention on her mental states and thematizes their intentional contents or makes explicit their phenomenological feature of their being her own states. On a very liberal reading of reflective self-awareness, we might admit, then, that groups are able to introspect in this way and may even lay a claim on their ownership of some mental states. Thus, groups may say via a spokesperson things like "It was not you alone (pointing to a member) but us who had this idea!" However, I contend that the very concept of self-awareness waters

\footnotetext{
${ }^{8}$ Note that none of this, just as little, incidentally, as immunity to misidentification, implies that subjects are incorrigible, let alone infallible, with regard to the self-ascription of any specific mental properties or referential object of their conscious states.

${ }^{9}$ As Rosenthal (1990) has prominently argued, the same goes for the non-identity of having conscious (mental) states (thus instantiating the property of "intransitive consciousness") and having mental states simpliciter.
} 
down too much if we were to subsume such cases under its heading. As to prereflective self-awareness, the case is even more obvious. It entails, minimally, a nonthematic being aware of a given mental state $\mathrm{M}$ at $t$ as one's own, to wit, by the very subject who instantiates $\mathrm{M}$ at $t$. Since groups supervene on the integrates of mental states of individuals, there cannot be a pre-reflective self-awareness of a group's mental state, nor as being any of those subject's mental states, let alone that of some supra-individual entity.

Note that these restrictions do not conflict with the positive requirement that there be individual conscious recognition - or awareness - of the unity and the existence of the group and its rational standpoint by each and every member qua member. Following Gilbert (1989, p. 223), we may call this the "recognition corollary".

Moreover, in spite of lacking a phenomenological first-person perspective, by using we-mode (Tuomela 2007) mental self-ascriptions in the first-person plural ("We believe that $p$ ", "We intend to $J$ '), the group may refer to its own epistemic standpoint and, eventually, self-reflectively identify with it. It may thus exhibit a kind of "corporate self-identification" (List and Pettit 2011, pp. 191-195), which, if successful, facilitates to identify its own we-personal point of view. This enables groups to make avowals such as "Having considered all our moral values and legal norms, we, members of the Supreme Court, believe that $p$." Their members too can be said to refer to themselves as members by identifying with the group's point of view. They can endorse the group's point of view in a more or less habitual fashion, without necessarily consulting their own first-person point of view or individual epistemic evidences. The members' attitudes regarding common practical and epistemic goals may thus be directly guided by the rational standards of the group (cf. List and Pettit 2011, p. 192).

Now, Schmid (2013) has most recently claimed that there is a specific kind of selfawareness that collectives do exhibit, "plural self-awareness," and which constitutes a we-mode perspective in the first place. Accordingly, plural self-awareness is supposed to be a "pre-reflective, non-thematic awareness of our attitudes as ours, collectively, in a way that makes the social sharedness of those attitudes phenomenally transparent to us, constitutes a shared perspective, and normatively drives us towards consistency of our attitudes" (Schmid 2013). Notice that such self-awareness "comes in the plural," that is, no supra-individual is said to be self-aware here. However, if genuine phenomenal transparency is at issue, only individuals, and let them be in the plural, come into consideration. The zombie conception of group minds proposed here can well accommodate such (individual, if shared) selfawareness, even though I believe that reference to the recognition corollary and, possibly, corporate self-identification well suffice for that matter. Moreover, if plural self-awareness is supposed to be necessary for normative consistency, then again, I take it, that the requirements of rationality, explicitly (i.e., not non-thematically) acknowledged by members in processes of group reasoning and deliberation, bear sufficient normative force without the need for positing a novel kind of selfawareness.

Coming back to the property of consciousness in particular, it is obvious that just as I cannot be conscious of the mental state you are in, no set of individuals, let alone some supra-individual entity, can be conscious of the mental contents of any given individual. Furthermore, notice another peculiarity of the property of consciousness. 
Consciousness seems to be a kind of "unitary" property in the following sense: Whether or not there is such a thing as unity of consciousness or a stream of consciousness that remains identical over time, the property of consciousness is essentially such that instances of that property are not divisible over or across more than the single subject that instantiates that property at a given time. Hence, no group of minds can instantiate the same token of any given conscious property.

To see this point more clearly, consider what it would mean to say that groups have consciousness or some other experiential contents. I take it that there are two possible readings of this claim: First, on the weaker, individualist reading, it would simply mean that there are some conscious experiential states in an individual subject S's mind whose very phenomenal content is such that it essentially includes reference to S's being a member of a group or pertains to some shared experience or to a collectivity as such. For example, this is the case if my mourning for the loss of a teammate has a specific phenomenal quality that it would lack were I the only one to mourn. I contend that according to this individualistic reading, there may be some form of collective consciousness, but this amounts to saying nothing more than saying that individuals can have communal experiences or some shared experiential/representational contents. At any rate, the zombie conception is noncommittal to such shared experiences (nor for that matter as to collective emotions; cf., e.g., Schmid 2009; Huebner 2011b; Salmela 2012).

Secondly, one could take a stronger, collectivist reading of the above claim. This amounts to saying that there is a phenomenally conscious integrity at the group level such that there are not only shared experiential contents, of which individuals are aware, but, rather, a supra-individual experiential unity or some sort of a communal stream of consciousness. Only in this latter case can we sensibly say that there could be such a thing as collective self-awareness and hence consciousness in the full sense. However, given the essentially first-personal character of experiences, the supraindividual entity would have to be, in turn, an individual subject of its own for whom there is something it is like to have those experiences, in which case it is no longer a supra-individual or collective entity. To conclude, we may all share the same experiences (or even emotions), and it may well be built into the phenomenal content of that same experience that we all partake in it, but there is literally no single supraindividual subject, no We, or any other entity who has that experience for its own.

Summing up, if these two requirements, the self-knowledge and consciousness restriction for short, are jointly sufficient to mark an epistemological difference between mental states (of groups) and conscious states (of individuals), then the obvious result is that the mental states of groups are neither (intentionally and/or phenomenally) conscious states nor are they states of a collective consciousness. Moreover, there is no direct metaphysical, causal, or epistemological route from one domain to the other. That is, the mental properties of groups are, as it were, written in a different metaphysical story than the conscious properties of individuals. All that links them exists nowhere else than within the (conscious) minds of individuals.

An important point here is that these requirements not only constitute negative restrictions on group minds, but they also have a positive impact: in order to account for a plurality of members within a group, there must be an epistemic asymmetry between those members. This is epistemologically guaranteed by 
the fact that there are a number of respectively privileged centers of consciousness that are not reducible to one another. Call this the "plurality condition" (Mathiesen 2005).

The upshot of this picture is this: groups with minds of their own do not have autonomous phenomenological capacities to epistemically reliably detect something extra- or intra-mental or to refer to themselves in a way that is immune to misidentification. They are not (pre-)reflectively self-aware or conscious of their own mental states. They lack some epistemic privileges of their members and have no cognitive capacities to make practical or theoretical inferences outright, without discursive and deliberative procedures, merely on the basis of being presented with some observational evidence. Finally, apart from the fact that they have no ordinary perceptual capacities of their own, they lack empathy, conations, or affective motivational sets. Call this the zombie conception of group minds (cf. for a similar recent suggestion O'Madagain 2012).

\section{Objections and replies}

At this point, some surely will resist the zombie conception of group minds, claiming that it leaves out some essential properties of the mental or, conversely, that this conception introduces some novel mental properties without further justification and does so counter-intuitively. Moreover, negative common sense as well as philosophical intuitions about zombies are so strongly entrenched that skeptics might view the zombie conception of group minds, far from being endorsement of GMT, as a strong reason to reject it, all the more so since it might give rise to general metaphysical concerns about watering down the boundaries of the mental or giving ammunition to functionalist-type reductionism.

More specifically, critics might object along four different lines, none of which counts, however, as a conclusive repudiation of a zombie-style defense of GMT, or so I shall argue.

1. Opponents will typically insist that what is central to the sense of the predicate "mental" both in common sense or folk ascriptions as well as for philosophical or scientific applications entails precisely those features that are not part of the zombie conception: in particular, consciousness, self-awareness, or non-inferential selfknowledge that is immune to misidentification (Mathiesen 2005; Rupert 2005). Such critics will, in other words, either claim that the zombie conception radically departs from ordinary use of what minds are or they will argue that the conception leaves out some essential or intrinsic properties of minds. As a familiar argument against zombie arguments goes, zombies may be logically but not metaphysically possible. This line of anti-zombie argument, however, does not apply to our collective type zombies. In the first place, we are concerned here with mental, not conscious properties. Secondly, the zombie conception argued for here says nothing for or against a metaphysical reduction of collective mental properties. Moreover, and this is more to the point in the present context, consider that zombies in the sense sketched above are epistemologically (and cognitively) highly sensible entities. They exhibit high degrees of practical and theoretical rationality. They have a unified intentional and rational 
vision of their own goals, actions, and thoughts as well as an overall unified stance towards them. They are sensible to norms. They are capable of selfevaluation and correction. They have means of linguistic, symbolic representation. They can communicate, vote, set up rules, deliberate, and can manipulate their cognitive environment. Moreover, they exhibit a complex internal mental architecture (such as an organizational structure, holistic determination of mental content, etc.). What else might we reasonably expect from attributing mental properties to some entity? Besides, the predicates "mental" and "consciousness" are not synonyms, neither in everyday nor in philosophical usage. Thus, we typically ascribe a whole range of significant properties to the mental but not necessarily to the more limited sphere of consciousness: these include symbolic or intentional representation, rationality, sensibility to norms, and some cognitive architecture. ${ }^{10}$ This is not meant to deny some principle of structural, functional, (meta-)physical, or other isomorphism or coherence between the conscious and the mental domain (Chalmers 1996). All I am claiming here is that cognitive processes, and the mental more generally, neither conceptually nor metaphysically entail the property of being conscious. The zombie conception serves to illustrate my point that there actually is no such entailment in the case of group-level mental properties.

2. A related metaphysical worry might be that on the zombie account groups may exhibit metaphysically genuinely novel mental properties, i.e., mental properties that are exclusively group properties. According to this concern, groups may bear mental properties that no other entity and especially no individual subject bears, to wit, non-conscious mental properties. Here, I agree, but this offers no challenge to GMT. Moreover, this implication is not surprising, given that group minds are, as already stated, different from individual minds. The difference between them is not a difference that lies in the metaphysical nature of their respective mental properties but between the vehicles that instantiate these properties. In one case, these vehicles are the minds of individuals who are eventually conscious subjects; in the other, they are groups that are not themselves conscious subjects but socially integrated collectives of conscious subjects (cf. Tollefsen 2002c).

3. Another more specific type of argument against the view that groups can literally have mental states has been raised in terms of a collective acceptance view of group attitudes and collective intentionality (Tuomela 2000; 2007; Wray 2001). The objection - which has been, notably, raised against Gilbert's (1989) conception of collective beliefs constituted by joint commitments - trades on the distinction between "collective belief" and "collective acceptance." According to this line of argumentation, groups do not have beliefs proper, which only individuals can have. Instead, the intentional attitudes that guide groups' actions are contents of collective acceptance. The difference is that individuals cannot entertain beliefs they know to be false because only individual subjects have the "disposition to feel that what they

\footnotetext{
${ }^{10}$ Compare that list with Rupert's tentative enumeration of significant properties that group minds shall instantiate in order to be regarded as genuinely mental entities: "the representational, computational, rational, perceptual, and architectural properties of minds” (Rupert 2005, p. 178).
} 
believe is true" (Wray 2001, p. 326). Where this disposition may "erode," they will change the respective belief. However, no one could change her belief that $p$ "at will." In contrast, groups lacking such dispositions altogether may well adopt views that run counter to the relevant evidence or beliefs of individual members. Since acceptance (both individual and collective) is "voluntary," "decidable at will" (Cohen 1989, p. 369), and, more importantly, "tailored to" specific goals and purposes (Wray 2001, p. $325)$, it can be modified deliberately as means to realize some common collectively accepted goal. Eventually, one might generalize this argument and claim that groups cannot have their own intentional or mental states, i.e., states with proper epistemic content, where epistemological standards of truth and falsity apply, but instead merely a collectively accepted "view" on which to base inferences regarding what to do, where only practical considerations, such as means to ends deliberation, are in play.

There are several ways to reply to this objection. To begin with, skepticism has been raised as to how deep the distinction between belief and acceptance runs and, in particular, whether it amounts to differences as to nature of belief and acceptance or rather to the nature of the respective subjects. It has been argued that groups, unlike individuals, may well form and change beliefs voluntarily and that this is a form of control over their doxastic attitudes. As already pointed out, here too, the difference lies in the nature of the respective subjects (groups or individuals) of beliefs and not in the nature of these attitudes themselves. One could equally refer to the fact that intentional states are dependent on having beliefs, so that unless groups have beliefs proper they could not have intentional attitudes, and among them collective goals, altogether (cf. Tollefsen 2002c). Though I do not hold that the intentionality of mental states simpliciter requires belief in a determinate proposition, for I oppose propositionalism with view to individual intentional states (Szanto 2012), I take it that a group's mental states must be such that their content is propositional content or is potentially translatable to reports about propositional attitudes. Here again, there is a difference between individuals and groups having mental states, but it does not follow that groups simply do not have mental states.

In addition, there are two others reasons, why I believe that the collective acceptance view does not challenge GMT: First, note that the contentious issue here is not whether groups may have intentional attitudes or mental states as such but, rather, whether these are to be construed as acceptance or belief. Hardly anybody, except much-contested intentional eliminativists, denies that acceptance is some sort of cognitive, intentional, or mental phenomenon. Accordingly, Wray, too, says that belief and acceptance are, though distinct, both "cognitive states" (Wray 2001, p. 326). ${ }^{11}$ Secondly, recall that I have defined the ascription of mental properties to collectives in terms of the collective having a rationally unified point of view and that this standpoint imposes normative requirements on the bearer of such a view. Consider that there is a constitutive two-way entailment between acceptance of or belief in both epistemically and practically coherent views and goals on the one hand and having a self-unifying rational point of view on the other. Because of that entailment just as groups cannot "at will" accept some view or (sub-)goal that runs counter to other relevant views or an overall goal, they also cannot form or entertain

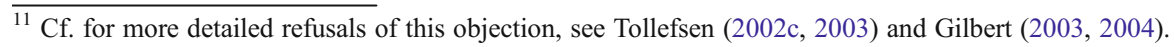


beliefs that run counter relevant evidence-or else they cannot be cannot be said to have a unified rational point of view in the first place. Furthermore, given that any evaluation of forming and changing views, even if they only concern practical matters, typically relies on basic epistemic standards of rationality, third parties could not understand why a group accepts a given view or act in light of such a view solely on the basis of practical standards. Thus, no group can change at will its collectively accepted views, intentions, or eventually its beliefs, in a way contrary to its other views about some ends or means without equal disintegration of its rational point of view or at least an irrational polarization of views, for instance due to some irrational biases, time pressure, etc. Changes in views will, at any rate, necessarily entail changes in the web of reasons unifying the rational point of view of the group. In those cases where we have such changes at will, what we have is either an authoritarian dictate, or nonrational pressure on the group, or else an instance of collective practical irrationality. In the former cases, there is no self-unified standpoint and hence no robust group mental attitudes; in the latter, there must be some form of practically motivated self-deception on the group level about the collective goals or the means to be taken or cases of akratic belief formation or action (cf. Pettit 2003b).

4. Last but not least, an important series of objections has been raised by Rupert $(2005,2011)$ regarding fine-grained differences in the functional and cognitive architecture, as well as the physical realization and the semantics of mental representations on the individual and the collective level. This objection emphasizes, amongst others, obvious differences between mental representations and pieces of linguistic or symbolic deliverances of corporate agents, such as a court's written statement, and the "privileged role to perceptual or quasiperceptual processing in individual mental representation" (Rupert 2005, p. 181). Accordingly, one may wonder whether the linguistic, inferential, and representational features of groups are not simply derived from the respective intentional capacities of individuals. Here, one may hold that in the case of individuals, intentionality is non-derivative with respect to linguistic processes (cf. Searle 1992; Adams and Aizawa 2001). Furthermore, Rupert has pointed to the lack of causal interaction with the (perceptual) environment on the part of groups and the lack of sensomotoric control and appropriate cognitive navigation within the environment. This, in turn, is supposed to result in failures to accommodate group cognition within the respective theories of our best cognitive science. Since in this paper I am not concerned with any particular version of the group cognition thesis, to which this series of objections primarily pertains, I can restrict myself to delineating the most salient problems of such arguments against collective mental representations (see for a detailed rejoinder Huebner 2008).

First, concerning the linguistic discursive and inferential features, note that one may well hold that intentionality is non-derived relative to linguistic semanticity and also that the capacity of discursive reasoning is only ascribable to individuals. I see, however, no reason why this should entail the furtherreaching thesis that groups could not have certain discursive and inferential features or structures sui generis, or that they are reducible to those of individuals. Furthermore, symbolic or linguistic representations are only the 
canonical results of a group's cognitive and deliberative processes, or its collective reasoning, just as are in fact linguistic expressions of individual mental representations. As such, they may indeed figure rather as the subject matter of linguistics than that of the cognitive sciences or a philosophy of mind. That does not, however, establish anything as to the underlying collective cognitive processes that constitute such results.

Secondly, consider the alleged causal interaction, cognitive control, and navigation problem: Groups do indeed not enter in causal relations with their environment via ordinary perceptions or sensomotoric activity. As recent research in socially distributed cognition has shown, however, groups do have a variety of proper means to interact, manipulate, control, and navigate within their cognitive and above all their social environment. These means range from technologically mediated devices of filtering or distributing information across members, allocating decision mechanisms among subgroups or members to collaborative forms of information gathering, issuing and co-authoring corporate statements, or co-authorizing institutional policies (cf. Hutchins 1995; Hinsz et al. 1997; MacKay 1999; Grosz and Hunsberger 2006; Baber et al. 2006; Goldstone et al. 2008). Furthermore, the fact that institutions may enter into specific representational relations with environments that are not identical with the perceptual or social environment of any of their members, and the fact that such group-level representations may eventually have causal feedback effects on the mental representations of those members, supports the assumption that we need a proper theory of how collective- and individual-level representations relate. Take, for instance, a court issuing a cumulatively drafted document, which then has a retroactive effect on the mental representations of the individual judges.

More generally, note that no, however fine- or coarse-grained differences in the architecture, formation, material realization, and/or the vehicles of collective- and individual-level mental states ${ }^{12}$ per se justify the conclusion that the ones are mental while the others are not. To claim otherwise means to claim that differences in the vehicle or bearer of the mental states would be sufficient to make up for differences in their respective epistemic contents and properties. But this amounts to succumbing to a crude vehicle/content-type fallacy. Moreover, to confine minds to the typical locus of their (individual) psycho-physical realization means to beg the question of what a mind is. In contrast, I shall argue in the remainder that what really matters about minds are not facts about their bearers, but their epistemic properties.

\section{The argument from epistemological irreducibility}

So far, I have argued that given the above three requirements, the intentionality, rationality, and integrity requirement, groups of individuals can constitute mental systems of their own even though they lack certain phenomenological and epistemic properties of individual minds. These requirements, apart from some terminological

\footnotetext{
${ }^{12}$ Note, however, that there is much support from cognitive science (cf. esp. Huebner 2008) that as to their representational properties, even at a sufficiently fine-grained level, differences are not as significant as often claimed.
} 
issues regarding the integrity requirement and the conception of rational points of view that it entails, are rather uncontroversial when taken to apply to individuals. They formulate standard requirements for intentional agency and theoretical and practical rationality. The question, then, is whether there are, above and beyond the objections to the zombie conception proper, any deep theoretical reasons why they might not apply to groups of individuals. And what explanatory role do they have if applied to groups?

Arguments from explanatory superfluity against GMT typically proceed as follows: One takes a propositional attitude ascription like "General Motors believes that the restrictive US tax legislations should be met by invigorating new output markets" and then one shows that both the cognitive genesis that led to the formation of such an allegedly group belief as well as their causal effects on subsequent events can be fully explained by tracing it back to individuals coming together, debating in meetings of the advisory board, issuing statements, etc., which then leads individuals to take appropriate measures. Hence, one concludes that there are no further psychological, causal, or cognitive data that one needs to cite.

There are several possible rejoinders to this line of thought: First, note that such a deflationist strategy eventually leads to an eliminativism which can be just as well, and just as controversially, leveled with view to the relation of individual's mental predicates, their neurophysiological underpinnings, and causal effects (cf. Clark 1994; Huebner 2008); merely alluding to some allegedly significant differences in our understanding of the respective "inter-level relations" (Rupert 2005, p. 180) or a difference between "intra- and inter-domain elimination" (Rupert 2011, p. 636) won't do for marking a difference in the prospects for such reductions. Surely, our understanding of how the respective reductive explanations in the two domains (the mental/physical and the group/individual-level) might, if successful, proceed, differ significantly. This by itself, however, has no effect whatsoever as to whether any of these reductions eventually succeed or not. Moreover, as I shall argue, such reduction of group beliefs to individual beliefs will in certain cases in fact not succeed.

Secondly, recall that even if we grant that the formation, realization and the causal effects of group mental states can be explained by tracing them back to individuals, the very mental content and its epistemological effects (on what the group infers, what further attitudes it forms, etc.) are such that it cannot be sensibly attributed to any individual alone or their aggregate. It is one thing to say how a group comes to believe what it believes (through deliberation, discussion, etc., in which individuals are engaged) and what feedback effects this might have on those individuals. It is quite another thing to say what mental content or what relevant beliefs are had as a result of individuals sharing mental states in the first place and what epistemological feedback such collective reasoning has on the individual mind sets as well as the (organizational) relations holding between individual's mind sets. The very possibility of there being such epistemic feedback means that group-level contents cannot be identical with individual-level mental contents. Moreover, as List and Pettit rightly observe, such epistemic feedback suggests that we may well introduce proper causal relations between the group and the individual level (List and Pettit 2011, p. 63).

Thirdly, the fact that at each step of a group deliberation one may have individual attitudes towards group beliefs or individual or majoritarian votes on them (Rupert 2005, p. 179) is 
beside the point. Clearly, individuals may have group-related attitudes, but there may equally be group beliefs without any such, or there may be some other relevant epistemological mismatch between group- and individual-level mental contents.

What, then, do these latter cases show? In their most general form, such discontinuities suggest that there are cases where no majoritarian votes or other aggregation functions of individual mental contents determine the group-level mental contents. They do so, by showing either: (a) that there can be different or even logically incompatible group- and individual-level attitudes without violating norms of rationality, or (b) that there may be no group-level contents that relevantly correspond to attitudes held by the majority or even any single individual member. I shall not dwell upon specifying such possibilities, which are saliently exemplified, e.g., by the muchdiscussed discursive dilemmas, and explored in great detail in the work of Gilbert, Pettit, List and others (esp. Gilbert 2004, Pettit 2003; List and Pettit 2011; cf. also Gold and Sudgen 2007). Instead, given such cases and building on the above requirements of rational integration, I suggest extrapolating the following argument, the argument from epistemological irreducibility, for GMT:

1. There are some mental states $M$ whose intentional-cum-epistemic content is constituted by a social integrate (SI) with a unified rational point of view.

2. The conditions of individuation of $M$ are holistically fixed by all relevant states of SI and all properties of SI (including its compositional structure and, ultimately, its own rational point of view), such that without knowing all relevant states of and facts about SI, one cannot know or reliably infer the content of $\mathrm{M}$ even if one were to know all the relevant facts about all individuals upon whom SI supervenes separately.

3. Moreover, $\mathrm{M}$ can be instantiated at $t$ without any corresponding mental states $\mathrm{M}^{*}$ of individuals upon whom SI at $t$ supervenes.

4. Given (2) and (3), $M$ and $M^{*}$ instantiate different epistemic properties.

5. M cannot epistemologically or explanatorily be reduced to any individual $\mathrm{M}^{*}$ but are properties of a (group) mind sui generis.

As to the explanatory power of postulating group-level mental properties, consider that in all cases where (2) and/or (3) obtains (essentially in one of the cases mentioned above), it is more than just "highly useful" or "meaningful" to treat groups by way of analogy or metaphorically as persons or agents who judge, intend or act (Tuomela 2007 , p. 145), or to construe them as "true believers" in an instrumentalist fashion à la Dennett (Clark 1994), or an interpretationist fashion à la Davidson (Tollefsen 2002a, b, c). Rather, in all such cases, if we want to properly describe, explain, and evaluate the epistemological machinery of a given group, both from a member's as well as from a third party perspective, it is an explanatory necessity to directly refer to the group's own rational point of view. Given my construal of collective mentality, if such reference is justified, it is equally justified to say that groups, literally, have mental states. $^{13}$

\footnotetext{
${ }^{13}$ Notice that the version of GMT advocated here is considerably stronger than the social manifestation thesis, according to which groups do not literally have mental properties even if some mental properties of individuals are only manifested when those individuals constitute some social collectives (cf. Wilson 2004, 299ff.).
} 


\section{Conclusion}

Social ontology must directly confront the hypothesis that there are groups with genuine minds of their own. As a first step down this road, I have attempted to demonstrate that given specific rational integration of the mental properties of individuals, individuals can in fact share mental properties that are not their own property, as it were, precisely because those are properties of a group with a mind of its own.

In order to do so, I have suggested to keep apart mental properties and conscious properties and put forward the zombie conception of group minds. I have argued that the zombie conception is immune to a number of negative intuitions raised against zombies, as well as to standard challenges of GMT. Moreover, I have shown that groups can indeed instantiate central properties of minds, as they are commonly conceived. Furthermore, based on the argument from epistemological irreducibility, I have shown that these properties not only have causal and explanatory power but that it is, in some cases, an explanatorily necessity to directly refer to them. I contend that the burden of proof now lies on the side of those who argue that individuals cannot share cognitive or mental properties because there is no such thing as a group with a mind of its own.

What is the more general metaphysical lesson of this? The lesson is that we should once and for all bid farewell both to individualism in the philosophy of mind as well as to singularism in the social ontology. We should, rather, think more seriously about an explanatory and ontological pluralism with view to the individuation of minds. Somewhat ironically, once we isolate conscious and mental properties, we may realize that to be mindful is a complex, multilayered phenomenon, not of a singular, intrinsic, or substantial but, eventually, of a corporate kind.

Acknowledgments I have presented earlier versions of this paper at the 2012 Conference of the Austrian Society of Philosophy (ÖGP) in Vienna, at the 2012 Meeting of the European Network on Social Ontology in Rome, and at colloquia at the Universities of Vienna and Klagenfurt. I have received valuable comments from the audiences at these events. For their comments on various drafts, I am especially indebted to Tim Burns, Wolfgang Fasching, Sophie Loidolt, Cathal O’Madagain, David Schweikard, Lukas Schwengerer, the editors of this special issue, Alessandro Salice, and Luca Tummolini, as well as two anonymous reviewers.

\section{References}

Adams, F., \& Aizawa, K. (2001). The bounds of cognition. Philosophical Psychology, 14(1), $43-64$.

Akkerman, S., Van den Bossche, P., Admiraal, W., Gijselaers, W., Segres, M., Simons, R.-J., \& Kirschner, P. (2007). Reconsidering group cognition: from conceptual confusion to a boundary area between cognitive and socio-cultural perspectives? Educational Research Review, 2(1), 39-63.

Baber, C., Smith, P., Cross, J., Hunter, J., \& McMaster, R. (2006). Crime scene investigation as distributed cognition. Pragmatics and Cognition, 14(2), 357-385.

Baier, A. (1997). Doing things with others: the mental commons. In L. Alanen, S. Heinämaa, \& T. Wallgren (Eds.), Commonality and particularity in ethics (pp. 15-44). Basingstoke: Palgrave Macmillan.

Barnier, A. J., Sutton, J., Harries, C. B., \& Wilson, R. A. (2008). A conceptual and empirical framework for the social distribution of cognition: the case of memory. Cognitive Systems Research, 9(1/2), 33-51.

Blomberg, O. (2009). Do socio-technical systems cognise? Proceedings of the 2nd Symposium on Computing and Philosophy: A Symposium at the AISB 2009 Convention (6-9 April 2009), 3-9. 
Bosse, T., Jonker, C., Shut, M., \& Treur, J. (2006). Collective representational content for shared extended mind. Cognitive Systems Research, 7(2/3), 151-174.

Bratman, M. (1992). Shared cooperative activity. Philosophical Review, 101(2), 327-341.

Bratman, M. (1993). Shared intention. Ethics, 104(1), 97-113.

Bratman, M. (1997). I intend that we $J$. In R. Tuomela \& G. Holstrom-Hintikka (Eds.), Contemporary action theory, vol. 2: social action (pp. 49-63). Dordrecht: Kluwer.

Brooks, D. H. M. (1986). Group minds. Australasian Journal of Philosophy, 64(4), 456-470.

Chalmers, D. (1996). The conscious mind: in search of a fundamental theory. Oxford: Oxford University Press.

Clark, A. (1994). Beliefs and desires incorporated. The Journal of Philosophy, 91(8), 404-425.

Cohen, J. L. (1989). Belief and acceptance. Mind, 98(391), 367-389.

Currie, G. (1984). Individualism and global supervenience. The British Journal for the Philosophy of Science, 35(4), 345-358.

Evans, G. (1982). The varieties of reference. Oxford: Oxford University Press.

French, P. A. (1979). The corporation as a moral person. American Philosophical Quarterly, 16(3), 207-215.

Gallagher, S. (2013). The socially extended mind. Cognitive Systems Research. doi:10.1016/j.cogsys. 2013.03.008

Giere, R. N. (2007). Distributed cognition without distributed knowing. Social Epistemology, 21(3), 313320.

Gilbert, M. (1989). On social facts. Princeton: Princeton University Press.

Gilbert, M. (1997). What is it for us to intend? In R. Tuomela \& G. Holstrom-Hintikka (Eds.), Contemporary action theory, vol. 2.: social action (pp. 65-85). Dordrecht: Kluwer.

Gilbert, M. (2003). Collective belief and acceptance. Protosociology, 16, 35-69.

Gilbert, M. (2004). Collective epistemology. Episteme, 1(2), 95-107.

Gilbert, M. (2006). A theory of political obligation: membership, commitment and the bonds of society. Oxford: Oxford University Press.

Gilbert, M. (2009). Shared intention and personal intention. Philosophical Studies, 144(1), 167-187.

Gold, N., \& Sudgen, R. (2007). Collective intentions and team agency. The Journal of Philosophy, 104(3), $109-137$.

Goldstone, R., Roberts, M. E., \& Gureckis, T. M. (2008). Emergent processes in group behavior. Current Directions in Psychological Science, 17(1), 10-15.

Grosz, B., \& Hunsberger, L. (2006). The dynamics of intention in collaborative activity. Cognitive Systems Research, 7(2/3), 259-272.

Gureckis, T. M., \& Goldstone, R. (2006). Thinking in groups. Pragmatics and Cognition, 14(2), $293-311$.

Gureckis, T. M., \& Goldstone, R. (2009). Collective behavior. Topics in Cognitive Science, 1(3), 412-438.

Harnad, S. (2005). Distributed processes, distributed cognizers, and collaborative cognition. Pragmatics and Cognition, 13(3), 501-514.

Hinsz, B. V., Vollrath, D. A., \& Tindale, R. S. (1997). The emerging conceptualization of groups as information processors. Psychological Bulletin, 121(1), 43-64.

Huebner, B. (2008). Do you see what we see? An investigation of an argument against collective representation. Philosophical Psychology, 21(1), 91-112.

Huebner, B. (2011a). Minimal minds. In L. Beauchamp Tom \& L. G. Frey (Eds.), The Oxford handbook of animal ethics (pp. 441-468). Oxford: Oxford University Press.

Huebner, B. (2011b). Genuinely collective emotions. European Journal for Philosophy of Science, 1(1), 89-118.

Huebner, B., Bruno, M., \& Sarkissian, H. (2010). What does the nation of China think about phenomenal states? Review of Philosophical Psychology, 1(2), 225-243.

Hutchins, E. (1995). Cognition in the Wild. Cambridge: MIT Press.

Janis, I. L. (1982). Groupthink. Boston: Wadsworth.

List, C., \& Pettit, P. (2011). Group agency: the possibility, design, and status of corporate agents. Oxford: Oxford University Press.

MacKay, W. E. (1999). Is paper safer? The role of paper flight strips in air traffic control. ACM Transactions on Computer-Human Interaction, 6(4), 311-340.

Mathiesen, K. (2005). Collective consciousness. In D. W. Smith \& A. L. Thomasson (Eds.), Phenomenology and philosophy of mind (pp. 235-250). Cambridge: Cambridge University Press.

Meijers, A. W. M. (2003). Can collective intentionality be individualized? American Journal of Economics and Sociology, 62(1), 167-183.

Miller, S. (2001). Social action: a teleological account. Cambridge: Cambridge University Press.

O'Madagain, C. (2012). Group agents: persons, mobs, or zombies? International Journal of Philosophical Studies, 20(2), 271-287.

Pettit, P. (2003a). Groups with minds of their own. In F. Schmitt (Ed.), Socializing metaphysics (pp. 167-193). New York: Rowman \& Littlefield. 
Pettit, P. (2003b). Akrasia, collective and individual. In S. Stroud \& C. Tappolet (Eds.), Weakness of will and practical irrationality (pp. 68-96). Oxford: Oxford University Press.

Pettit, P., \& Schweikard, D. (2006). Joint actions and group agents. Philosophy of the Social Sciences, $36(1), 18-39$.

Poirier, P., \& Chicoisne, G. (2006). A framework for thinking about distributed cognition. Pragmatics and Cognition, 14(2), 215-234.

Quinton, A. (1975/76). Social objects. Proceedings of the Aristotelian Society, 76, 1-27.

Rosenthal, D. (1990). A theory of consciousness. In N. Block, O. Flanagan, \& G. Güzeldere (Eds.), The nature of consciousness: philosophical debates (pp. 729-754). Cambridge: MIT Press.

Rovane, C. (1998). The bounds of agency: an essay in revisionary metaphysics. Princeton: Princeton University Press.

Rovane, C. (2004). Alienation and the alleged separateness of persons. The Monist, 87(4), 554-572.

Rupert, R. D. (2005). Minding one's cognitive systems: when does a group of minds constitute a single cognitive unit? Episteme, 1(3), 177-188.

Rupert, R. D. (2009). Cognitive systems and the extended mind. Oxford: Oxford University Press.

Rupert, R. D. (2011). Empirical arguments for group minds: a critical appraisal. Philosophy Compass, 6(9), 630-639.

Salmela, M. (2012). Shared emotions. Philosophical Explorations, 15(1), 33-46.

Schmid, H. B. (2009). Plural action: essays in philosophy and social science. Dordrecht: Springer.

Schmid, H. B. (2013). Plural self-awareness. In Phenomenology and the Cognitive Sciences (this issue).

Schmitt, F. (2003). Joint action from individualism to supra-individualism. In F. Schmitt (Ed.), Socializing metaphysics (pp. 129-165). New York: Rowman \& Littlefield.

Shoemaker, S. (1968). Self-reference and self-awareness. The Journal of Philosophy, 65(19), 555-567.

Smith, E. R. (2007). Social relationships and groups: new insights on embodied and distributed cognition. Cognitive Systems Research, 9(1/2), 24-32.

Searle, J. (1990). Collective intentions and actions. In P. Cohen, J. Morgan, \& M. E. Pollack (Eds.), Intentions in communication (pp. 401-415). Cambridge: MIT Press.

Searle, J. (1992). The rediscovery of the mind. Cambridge: MIT Press.

Searle, J. (2010). Making the social world: the structure of human civilization. Oxford: Oxford University Press.

Sheehy, P. (2006). The reality of social groups. Aldershot: Ashgate.

Stoutland, F. (1997). Why are philosophers of action so anti-social? In L. Alanen, S. Heinämaa, \& T. Wallgren (Eds.), Commonality and particularity in ethics (pp. 45-74). Basingstoke: Palgrave/Macmillan.

Stoutland, F. (2008). The ontology of social action. Analyse und Kritik, 28, 533-551.

Sunstein, C. R. (2002). The law of group polarization. Journal of Political Philosophy, 10(2), 175-195.

Sutton, J. (2006). Distributed cognition: domains and dimensions. Pragmatics and Cognition, 14(2), 235247.

Sutton, J., Harris, C. B., Keil, P. G., \& Barnier, A. J. (2010). The psychology of memory, extended cognition, and socially distributed remembering. Phenomenology and the Cognitive Sciences, 9(4), 521-560.

Szanto, T. (2012). Bewusstsein, Intentionalität und mentale Repräsentation. Husserl und die analytische Philosophie des Geistes. Berlin/Boston: De Gruyter.

Theiner, G., Allen, C., \& Goldstone, R. (2010). Recognizing group cognition. Cognitive Systems Research, 11(4), 378-395.

Theiner, G., \& O'Connor, T. (2010). The emergence of group cognition. In A. Corradini \& T. O’Connor (Eds.), Emergence in science and philosophy (pp. 79-117). New York: Routledge.

Thompson, L., \& Fine, G. A. (1999). Socially Shared Cognition, Affect, and Behavior: A Review and Integration. In Personality and Social Psychology Review, 3(4), 278-302.

Tollefsen, D. (2002a). Collective intentionality and the social sciences. Philosophy of the Social Sciences, $32(1), 25-50$.

Tollefsen, D. (2002b). Organizations as true believers. Journal of Social Philosophy, 33(3), 395-410.

Tollefsen, D. (2002c). Challenging epistemological individualism. Protosociology, 16, 86-117.

Tollefsen, D. (2003). Rejecting rejectionism. Protosociology, 18(19), 389-408.

Tollefsen, D. (2006). From extended mind to collective mind. Cognitive Systems Research, 7(2/3), 140-150.

Tuomela, R. (1989). Collective action, supervenience, and constitution. Synthese, 80(2), 243-266.

Tuomela, R. (2000). Belief vs. acceptance. Philosophical Explorations, 3(2), 122-137.

Tuomela, R. (2007). The philosophy of sociality: the shared point of view. Oxford: Oxford University Press.

Tuomela, R. (2013). Who is afraid of group agents and group minds? In M. Schmitz, B. Kobow, \& H. B. Schmid (Eds.), The background of social reality: selected contributions from the inaugural meeting of ENSO (pp. 13-36). Dordrecht: Springer.

Velleman, D. (1997). How to share an intention. Philosophy and Phenomenological Research, 57(1), $29-51$.

Wegner, D. M. (1987). Transactive memory: A contemporary analysis of the group mind. In B. Mullen \& G. R. Goethals (Eds.), Theories of group behavior. New York: Springer. 
Wilson, R. A. (2004). Boundaries of the mind: the individual in the fragile sciences-cognition. Cambridge: Cambridge University Press.

Wilson, R. A. (2005). Collective memory, group minds, and the extended mind thesis. Cognitive Processing, $6(4), 22-236$.

Wray, K. B. (2001). Collective belief and acceptance. Synthese, 129(3), 319-333.

Waytz, A., \& Young, L. (2012). The group-member mind trade-off: attributing mind to groups versus group members. Psychological Science, 23(1), 77-85. 